\title{
RASTREAMENTO DE NEOPLASIA INTRACERVICAL EM UM GRUPO DE MULHERES PORTADORAS DE VÍRUS DA IMUNODEFICIÊNCIA HUMANA. PROCURA POR NEOPLASIA INTRACERVICAL EM MULHERES SOROPOSITIVAS
}

\author{
A SEARCH FOR INTRACERVICAL NEOPLASIA IN A GROUP OF WOMEN \\ BEARING THE HUMAN IMMUNODEFICIENCY VIRUS. \\ A SEARCH FOR INTRACERVICAL NEOPLASIA IN WOMEN WITH THE \\ HIV VIRUS
}

\author{
Helder Ferreira ${ }^{1 *}$, Eliane Raquel Peres Lala ${ }^{2}$, Kátia Pereira Borba ${ }^{3}$ \\ 1* Autor para contato: Universidade Estadual de Maringá - UEM, Programa de Pós-Graduação \\ em Análises Clínicas, Maringá, PR, Brasil; (44)3263-0821; e-mail: ferreira.helder@bol.com.br \\ 2 Universidade Estadual de Maringá - UEM, Programa de Pós-Graduação em Ciências \\ da Saúde, Maringá, PR \\ 3 Universidade Estadual do Centro Oeste - UNICENTRO, Departamento de Enfermagem, \\ Guarapuava, PR
}

Recebido para publicação em 04/05/2006

Aceito para publicação em 02/08/2006

\section{RESUMO}

Manifestações de doenças oportunistas como candidíase vulvovaginal, infecção pelo papilomavírus humano (HPV) e as neoplasias intra-epiteliais cervicais (NIC) são catalogados como manifestações da AIDS na mulher soropositiva. Vários estudos têm evidenciado que em mulheres portadoras de HIV, observa-se maior incidência de infecção do trato genital inferior pelo HPV. Isto é relevante, pois a infecção pelo papilomavírus humano (HPV) é vinculada ao desenvolvimento de neoplasia cervical, associação claramente estabelecida há tempos. Encontramse na literatura vários relatos que apontam uma freqüência significativa de NIC entre as mulheres infectadas pelo HIV, especialmente entre aquelas que apresentam algum grau de imunodepressão. Assim, estes dados nos levaram a investigar 30 mulheres HIV-soropositivas cadastradas no Centro de Orientação e Aconselhamento Sorológico (COAS), do município de Guarapuava-PR, no período de julho a outubro de 2004. As pacientes foram submetidas ao protocolo de atendimento ginecológico, que incluiu anamnese e exame ginecológico. Foram encontrados três casos (10\%) de NIC no grupo investigado, sendo dois $(6,6 \%)$ diagnosticados como NIC I e um (3,3\%) como NIC II. Dentre esses casos com NIC, em dois (66,6\%) havia indicação de infecção pelo papilomavírus humano. Concluindo, nossos dados sugerem que o HPV, assim como o NIC são patologias 
agravadas pelo vírus HIV.

Palavras-chave: papilomavirus humano, neoplasia intra cervical, HIV, rastreamento

\begin{abstract}
Frequent manifestations of opportunistical diseases such as vulvovaginal candidiasis, an infection caused by the human papillomavirus (HPV), and cervical intraepithelial neoplasia (NIC) are classified as manifestations of AIDS in HIVpositive women. Several studies have been evincing that in women who are HIV bearers, a larger incidence of infections by HPV in the inferior genital tract is observed. This is of great relevance, because the infection by the human papilomavirus (HPV) is linked to the development of cervical neoplasia, an association that has long since been clearly established. The specialized literature presents numerous reports that point to a significant frequency of NIC among women infected by HIV, especially among those that present a low degree of immunity.These data led us to investigate thirty cases of HIV-positive women registered in the "Centro de Orientação e Aconselhamento Sorológico" (COAS), of the municipal district of Guarapuava-PR, between July and October 2004. The patients were submitted to the protocol of gynaecological attendance that included anamnesis and a gynaecological exam. Three cases (10\%) of NIC were identified in the investigated group, two of which (6.6\%) were diagnosed as NIC I, and one (3.3\%) as NIC II. In two of these cases (66.6\%) there was an indication of infection by the human papillomavirus. Finally, our data suggests that HPV, as well as NIC are pathologies that are worsened by the HIV virus.
\end{abstract}

Key words: human papillomavirus, cervical intraepithelial neoplasia, HIV, tracing

\section{Introdução}

O HIV é o vírus causador da síndrome de imunodeficiência adquirida (AIDS), que compromete o funcionamento do sistema imunológico, impedindoo de executar sua tarefa de proteger o organismo contra as agressões externas (por bactérias, outros vírus e parasitas) e contra células cancerígenas. (Coelho, 2006).

Manifestações de doenças oportunistas ocorrem no trato genital feminino de mulheres portadoras de HIV. A candidíase vulvovaginal recorrente, infecção pelo papilomavírus humano (HPV), a doença inflamatória pélvica, o carcinoma invasor do colo uterino e as neoplasias intra-epiteliais cervicais (NIC) são catalogados como manifestações da AIDS na mulher soropositiva (CDC,1992). Após decorrido mais de duas décadas de epidemia de AIDS, estatísticas mundiais indicam pela primeira vez números iguais para homens e mulheres infectados com o vírus HIV. As mulheres também já representam metade dos casos infectados entre indivíduos jovens entre 15 e 24 anos (Johnson et al., 1992).

Vários estudos têm evidenciado que em mulheres portadoras de HIV, observa-se maior incidência de infecção do trato genital inferior pelo HPV (Auge et al., 2000). É relevante o fato de que a infecção por papilomavírus humano (HPV) é vinculada ao desenvolvimento de neoplasia cervical, associação claramente estabelecida há tempos (Araújo et al., 2005). Existe na literatura uma concordância de idéias quanto à associação do DNA-HPV com as neoplasias intra-epiteliais cervicais e câncer cervical (Campos et al., 2000; Wieland e Pfister, 1999). Encontram-se 
relatos que entre 93 e 100\% dos carcinomas de células escamosas da cérvice uterina contêm DNA-HPV de alto grau, transmitido durante o ato sexual (Campos et al., 2000). Muñoz (2003) aponta que estudos multicêntricos envolvendo aproximadamente 2000 pacientes portadoras de câncer cervical de células escamosas identificaram como de alto risco com potencial carcinogênico os HPVs dos tipos 16, 18, 31, 33, 35, 39, 45, 51, 52, 56, 58, 59, 68, 73 e 82.

Por si, o HIV é indicado como um fator independente para a infecção do HPV anogenital tanto na forma latente quanto na forma evidenciada clinicamente nas mulheres, principalmente pela neoplasia intra-epitelial cervical (Campos et al., 2000; Wieland e Pfister, 1999). Um estudo realizado por Campos et al. (2000) no município de Betim, Minas Gerais, com o objetivo de avaliar a prevalência do HPV e seus genótipos, utilizando a técnica de reação em cadeia de polimerase (PCR), em pacientes soropositivas e soronegativas para o HIV, chegou ao resultado que pacientes infectadas pelo HIV, 73,2\% apresentaram resultado positivo para o DNA-HPV, comparado a 23,8\% dentre as soronegativas, portanto, as mulheres soropositivas pelo HIV apresentaram maior prevalência do DNA-HPV na cérvice uterina, em relação as soronegativas.

Paralelamente a esses estudos, encontra-se na literatura relatos que apontam uma freqüência significativa de NIC entre as mulheres infectadas pelo HIV, especialmente entre aquelas que apresentam algum grau de imunodepressão (Silva e Reis, 2003; Bongain et al., 1996; Auge et al. 2000; Heard et al., 2000).

A relação entre o vírus da imunodeficiência humana (HIV) e a neoplasia do colo uterino foi suspeitada pela primeira vez em 1988 (Araújo et al., 2005). Esta correlação se fortaleceu adquirindo nova importância no estudo da infecção pelo HIV quando o Centro de Prevenção e Controle de Doenças (CDC) considerou o carcinoma cervical invasivo como condição indicadora de AIDS, independente do valor da contagem dos linfócitos T CD4 ${ }^{+}$. Segundo Davis et al. (2001) mulheres infectadas pelo HIV podem ter prevalência dez vezes maior de lesão intra-epitelial escamosa cervical, quando comparadas a pacientes soronegativas para o HIV. O HPV é detectado por meio do exame citologia oncótica (papanicolau) realizado pela rede básica de saúde. O exame citológico de Papanicolaou é o método de excelência na avaliação do grau de alteração celular do epitélio escamoso cervical, e tem ajudado a diminuir drasticamente a incidência de câncer de colo uterino (Tuon et al., 2002).

O objetivo do trabalho foi rastrear a neoplasia intracervical em um grupo de mulheres portadoras do vírus HIV, registradas no Centro de Orientação e Aconselhamento Sorológico (COAS), do Município de Guarapuava.

\section{Materiais e métodos}

Trata-se de um estudo transversal, que é caracterizado pela investigação pontual, isto é, demonstra como as variáveis em estudo estão relacionadas no momento da investigação. Através deste estudo, obtém-se informações que possibilitam investigar a prevalência de eventos na amostra estudada e analisar a relação entre esses eventos, além da obtenção de outras características da amostra. (Pereira, 2000).

Foram acompanhadas 30 mulheres HIVsoropositivas cadastradas no Centro de Orientação e Aconselhamento Sorológico(COAS), do município de Guarapuava-PR, no período de julho a outubro de 2004. As pacientes foram submetidas ao protocolo de atendimento ginecológico que incluiu anamnese e exame ginecológico. O rastreamento do NIC e acompanhamento ginecológico destas pacientes vêm sendo realizados semestralmente, não se efetuando exclusivamente para fins de pesquisa.

O exame ginecológico e o rastreamento das Neoplasias intracervical foram realizados segundo o protocolo estabelecido: inspeção, introdução do espéculo vaginal e coleta de material para colpocitologia oncótica cervical (Papanicolaou).

O material citológico foi enviado ao Laboratório Central do Estado do Paraná (LACEN-PR). Os resultados desses exames retornaram ao COAS, que providenciou cuidados as pacientes com indicação de NIC.

\section{Resultados}

Foram estudadas 30 pacientes portadoras do 
HIV, em uso de uma ou mais drogas anti-retrovirais, independente do tempo de uso, até a data da colpocitologia oncótica cervical. A idade das mulheres do grupo variou entre 18 a 65 anos sendo a média de 40 anos. Quanto à escolaridade, 60 \% possuíam ensino fundamental incompleto, indicando baixa grau de instrução (Tabela 1). Notou-se que 59\% não possuíam parceiros fixo, sendo $21 \%$ separadas e $38 \%$ solteiras.

Conforme dados obtidos, das 30 pacientes portadoras do HIV em estudo, encontrou-se 03 casos (10\%) de NIC no grupo investigado, sendo duas $(6,6 \%)$ diagnosticada NIC I e uma (3,3\%) NIC II. Dentre estas mulheres com NIC, em 02 (66,6\%) havia indicação de infecção pelo papilomavírus humano (Tabela 2).

Tabela 1 - Grau de instrução e faixa etária de mulheres

\begin{tabular}{lccccc} 
& \multicolumn{4}{c}{ Grau de Instrução } & \\
\cline { 2 - 5 } Faixa etária & Analfabeto & $\begin{array}{c}\text { Fundamental } \\
\text { incompleto }\end{array}$ & $\begin{array}{c}\text { Fundamental } \\
\text { completo }\end{array}$ & $\begin{array}{c}\text { Ensino } \\
\text { Médio }\end{array}$ & Total \\
\hline Até 30 & & $5(16,7 \%)$ & & & $5(16,7 \%)$ \\
31 a 40 & $1(3,3 \%)$ & $3(10,0 \%)$ & $3(10,0 \%)$ & $1(3,3 \%)$ & $8(26,6 \%)$ \\
41 a 50 & $8(26,7 \%)$ & $4(13,3 \%)$ & $1(3,3 \%)$ & $13(43,3 \%)$ \\
Mais de 50 & & $2(6,7 \%)$ & & $2(6,6 \%)$ & $4(13,3 \%)$ \\
\hline Total & $1(3,3 \%)$ & $18(60,0 \%)$ & $7(23,3 \%)$ & $4(13,3 \%)$ & $30(100,0)$ \\
\hline
\end{tabular}

Tabela 2 - Relação entre HPV e NIC em mulheres

\begin{tabular}{cccc}
\hline & \multicolumn{3}{c}{ NIC } \\
\hline HPV & I & II & Total \\
\hline Presente & $1(33,3 \%)$ & $1(33,3 \%)$ & $2(66,6 \%)$ \\
Ausente & $1(33,3 \%)$ & & $1(33,3 \%)$ \\
\hline Total & $2(66,6 \%)$ & $1(3,33 \%)$ & $3(100,0 \%)$ \\
\hline
\end{tabular}

\section{Discussão}

Embora o HPV não tenha sido motivo deste estudo, chama a atenção o alto índice de mulheres portadoras de NIC com indicação de HPV (Tabela 1). Autores relatam que a sua alta prevalência, assim como a sua persistência na cérvice uterina em mulheres HIV-positivas, interferem ou não na presença, evolução ou involução das lesões cervicais em mulheres usando anti-retrovirais (Araújo et al., 2005; Lillo et al., 2001). Nas pacientes HIV-soropositivas, a NIC é mais freqüente e recorrente, de evolução mais rápida, e não apresenta boa resposta ao tratamento convencional (Auge et al. 2000; Melo et al., 2003). Essa maior agressividade tem relação direta com os genótipos de alto risco do HPV, mais freqüentes na cérvix das mulheres HIV-soropositivas (Silva e Reis, 2003; Wallace, 2001).

Após um estudo clássico de Sillman et al. (1984) no qual se demonstrou aumento de risco para o aparecimento de infecção pelo HPV em mulheres imunodeprimidas devido ao uso de drogas e quimioterapia, alguns autores procuraram verificar a possível correlação entre a imunodepressão das portadoras do HIV e a freqüência de comprometimento do colo uterino pelo papilomavírus humano (Auge et al. 2000; Sillman et al., 1984; Johnson et al, 1992). Segundo Johnson et al. (1992), a incidência de infecção pelo HPV foi cinco vezes mais elevada entre as mulheres HIVsoropositivas que apresentavam níveis de linfócitos 
$\mathrm{CD}^{+}$abaixo de $200 / \mathrm{mm}^{3}$ quando comparadas com mulheres HIV-soropositivas imunocompetentes.

Outros trabalhos têm evidenciado que a freqüência de infecção pelo papilomavírus humano está relacionada com comprometimento pelo HIV (CDC, 1992; Levine, 2002; Auge et al. 2000; Heard et al., 2000; Wieland e Pfister, 1999). Sun e colaboradores (1995), verificaram significativa prevalência de infecção pelo HPV nas mulheres HIV-soropositivas. A taxa de infecção pelo papilomavírus humano foi de $60 \%$ entre as mulheres HIV-soropositivas, e de $36 \%$ no grupo controle. Este estudo investigou 344 portadoras do vírus da imunodeficiência humana e 325 mulheres HIVsoronegativas (grupo controle), nas quais foram utilizados colposcopia e teste do DNA do HPV. No Brasil foi observado a prevalência de 78 a $98 \%$ do HPV em mulheres soropositivas, empregando-se PCR, e de 64,5\% quando se utilizou a técnica da colposcopia (Auge et al. 2000; Melo et al., 2003; Sun et al., 1995). Em nosso estudo encontramos o índice de $10 \%$ de NIC e 66\% de HPV concordando com resultados encontrado nestes estudos.

\section{Conclusão}

A medida em que o número de mulheres contaminadas com o vírus HIV aumenta e que são disponibilizados fármacos capazes de controlar a doença e aumentar a sobrevida, teremos um maior contingente de mulheres portadoras do vírus a merecer cuidados na detecção do NIC como o rastreamento, e tratamento precoce das doenças relacionadas com a síndrome (AIDS).

\section{REFERÊNCIAS}

1. ARAÚJO, A. C. L.; MELO, V. H.; CASTRO, L. P. F.; GUIMARÃES, M. D. C.; ALEIXO, A.W.; SILVA, M. L. Associação entre a carga viral e os linfócitos T CD4 ${ }^{+}$com as lesões intra-epiteliais do colo uterino em mulheres infectadas pelo vírus da imunodeficiência humana. Rev. Bras. Ginecol. Obstet.; vol .27 no.3 Rio de Janeiro, 2005.

2. AUGE, A. P. F.; PIATO, S.; FRADE, A. B.; PAES, R. P.; MOURA, C. M. C.; SANTOS, A. L. D.; VAZ, A. Frequency of Cervical Intraepithelial Neoplasia in Human Immunodeficiency Virus-infected Women. Rev. Bras. Ginecol. Obstet., vol.22 n.9 Rio de Janeiro, 2000.

3. BONGAIN, A.; RAMPAL, A.; DURANT, J.; MICHIELS, J. F.; DELLAMONICA, P.; GILLET, J. Y. Cervical intra-epithelial neoplasia in women infected with human immunodeficiency virus. Eur J Obstet Gynecol Reprod Biol; vol.65 p.195-9, 1996.

4. CAMPOS, R. R.; MELO, V. H.; DEL CASTILHO, D. M.; NOGUEIRA, C. P. F. Prevalência do papilomavírus humano e seus genótipos em mulheres portadoras e não-portadoras do vírus da imunodeficiência humana. Rev. Bras. Ginecol. Obstet. vol.27 no.5 Rio de Janeiro, 2005

5. CENTER FOR DISEASE CONTROL AND PREVENTION. Revised classification system for HIV infection and expanded surveillance case definition for aids among adolescents and adults, 1993. MMWR. Recommendations and reports. v.41, n.RR-17, p.1-19, Atlanta, 1992.

6. COELHO, S.; AIDS. Disponivel em: <http://www.fiocruz.br/ ccs/glossario/aids.htm>. Acesso em 24 de junho de 2006.

7. DAVIS, A. T.; CHAKRABORTY, H.; FLOWERS, L.; MOSUNJAC, M.B. Cervical dysplasia in women infected with the human immunodeficiency virus (HIV): a correlation with HIV viral load and CD4+ count. Gynecol Oncol., vol.80 n.3 p.350-4, 2001.

8. HEARD, I.; TASSIE, J. M.; SCHMITZ, V.; MANDELBROT, L.; KAZATCHKINE, M. D.; ORTH, G. Increased risk of cervical disease among human immunodeficiency virus-infected women with severe immunosuppression and high human papilomavírus load. Obstet Gynecol. vol.96 n.3 p.403-9, 2000.

9. JOHNSON, J. C.; BURNETT, A. F.; WILLET, G. D.; YOUNG, M. A.; DONIGER, J. High frequency of latent and clinical human papillomavirus cervical infection in immunocompromised human immunodeficiency virus-infected women. Obstet Gynecol.; vol.79 p.321-7, 1992.

10. LEVINE, A. M. Evaluation and management of HIV-infected women. Ann Intern Med; vol.136 p.228-42, 2002.

11. LILLO, F. B.; FERRARI, D.; VEGLIA, F.; ORIGONI, M.; GRASSO, M.A.; LODINI, S.; MASTRORILLI, E.; TACCAGNI, G.; LAZARRIN, A.; UBERTI-FOPPA, C. Human papillomavirus infection and associated cervical disease in human immunodeficiency virus-infected women: effect of highly active antiretroviral therapy. J.Infect.Dis, vol.184 n.5 p.54751, 2001.

12. MELO, V.H.; ARAÚJO, A. C. L.; RIO, S. M. P.; CASTRO, L. P. F.; AZEVEDO, A. A.; CASTRO, M. M. Problemas ginecológicos mais freqüentes em mulheres soropositivas para o HIV. Rev. Bras. Ginecol. Obstet. vol.25 n.9 Rio de Janeiro, 2003.

13. MUÑOZ, N.; BOSCH, F. X.; SANJOSÉ. S.; HENERO, R.; CATELLSAGUÉ, X.; SHAH, K. V.; SNIJDERS, P. F. J.; MEIJER, C. J. L. M. Epidemiologic classification of human papillomavirus types associated with cervical cancer. New Engl 
J Méd, vol.348 p.518-27, 2003.

14. PEREIRA, M. G. Epidemiologia: Teoria e Prática. 4 ed. Rio de Janeiro: Guanabara Koogan, 2000.

15. SILLMAN, F.; STANEK, A.; SEDLIS, A.; ROSENTHAL, J.; LANKS, K. W.; BUCHHAGEN, D.; NICASTRI, A.; BOYCE, J. The relationship between human papillomavirus and lower genital intraepithelial neoplasia in immunosuppressed women. Am J. Obstet. Gynecol.; vol.150 p.300-8, 1984.

16. SILVA, R. J. O.; REIS, A. F. F.; RUSSOMANO, F. B.; FIALHO, S. C. A. V.; GRINSZTEJN, B. Lesões intra-epiteliais do colo uterino em pacientes infectadas pelo HIV. J Bras Doenças Sex Transm.; vol.15 n.3 p.16-20, 2003.

17. SILVA, R. J. O.; REIS, A. F. F.; Estudo da prevalência e dos fatores associados às lesões intra-epiteliais escamosas do colo uterino em mulheres infectadas pelo HIV. Rev. Bras. Ginecol. Obstet. vol.25 no.8 Rio de Janeiro, 2003.
18. SUN, X. W.; ELLERBROCK, T. V.; LUNGU, O.; CHIASSON, M. A.; BUSH, T. J.; WRIGHT, T. C. Jr. Human papillomavirus infection in human immunodeficiency virus-seropositive women. Obstet Gynecol; vol.85 p.680-6, 1995.

19. TUON, F. F. B.; BITTENCOURT, M. S.; PANICHI, M. A. Avaliação da sensibilidade e especificidade dos exames citopatológico e colposcópico em relação ao exame histológico na identificação de lesões intra-epiteliais cervicais. Rev. Assoc. Med. Bras., vol.48, no.2, p.140-144.2002.

20. WALLACE, S. V.; CARLIN, E. M. HIV in cervical cancer. Int J. STD AIDS; vol.12, p.283-5, 2001.

21. WIELAND, U.; PFISTER, H. Papilomavírus em patologia humana: epidemiologia, patogênese e papel oncogênico. In: Gross G, Barrasso R, editores. Infecções por Papilomavírus Humano: Atlas clínico de HPV.1 $1^{\text {a }}$ ed. Porto Alegre: Artes Médicas;. p.1-18, 1999. 